\title{
Rio de Janeiro
}

National Cancer Institute

\section{Source}

National Cancer Institute. Rio de Janeiro. NCI Thesaurus. Code C156331.

A state in the Southeast Region of Brazil. Its capital is Rio de Janeiro. 